\title{
Educomunicação é para todos: a Itália visita o Nas Ondas do Rádio
}

Resumo: Em visita ao Brasil, como parte de seu programa de estudos em educomunicação, a professora italiana Isabella Bruni pôde visitar experiências nesse campo dentro da cidade de São Paulo e traçar um comparativo entre o trabalho realizado em diversas cidades italianas e os projetos brasileiros. Nesta entrevista, ela destaca as diferenças e semelhanças entre a educação nos dois países, tomando como base tradições culturais e políticas, e reflete a respeito das possibilidades do uso das ferramentas de comunicação em sala de aula - recursos, muitas vezes, mais familiares para os jovens do que para seus professores.

Palavras-chave: educação, comunicação, Itália, novas mídias, desenvolvimento social.

\begin{abstract}
Visiting Brazil as part of her educational communication program, the Italian teacher Isabella Bruni was able to visit experiences in this area within São Paulo city and outline a comparison between the work done in several Italian cities and the Brazilian projects. In this interview, she stands out the differences and similarities between the education in the two countries, based on cultural and political traditions, and thinks about the possibilities of using the communication tools in the classroom - resources that are already, frequently more familiar to young people than to their teachers.

Keywords: education, communication, Italy, new media, social development.
\end{abstract}

O interesse da professora italiana Isabella Bruni pela educomunicação começou na universidade, quando passou a desenvolver projetos sobre o uso do rádio e da internet no ambiente escolar. Mais tarde, conduziu-a a experiências práticas nas escolas italianas e, por fim, fez com que ela cruzasse o Atlântico para pesquisar como é a prática de educomunicação em São Paulo. Bolsista da Universidade La Sapienza, ela chegou ao Brasil no primeiro semestre de 2009 para acompanhar as atividades do projeto Nas Ondas do Rádio, desenvolvido nas escolas municipais da cidade de São Paulo. De volta à Itália, ela pretende unir a vivência das escolas paulistas ao conhecimento adquirido nas instituições italianas. Nesta entrevista ela traça um comparativo entre a educomunicação que se constrói no Brasil e o sistema educacional da Itália - numa reflexão que inclui, nos dois casos, o próprio desenvolvimento da relação entre professor e aluno.

\section{Por Juliana Winkel}

C\&E: Como foi o início do seu trabalho com educomunicação?

Isabella Bruni: Comecei a trabalhar com educomunicação quando fui a Roma fazer uma especialização. Desde 2006, trabalhei junto com a universidade, ao mesmo tempo que comecei a estudar a área, em conjunto com os professores. 
Fui educomunicadora em um projeto do Ministério de Educação da Itália, que foi o primeiro projeto oficial do Ministério sobre educomunicação. Era realizado em conjunto com as Associações de Pais em duas escolas, uma de Ensino Médio e outra de Ensino Superior. Realizávamos em conjunto laboratórios com alunos, pais e professores, fazendo uma reflexão sobre os meios de comunicação e, em particular, sobre a televisão. Depois desenvolvi atividades com rádio, que é o meio com que trabalho na Universidade La Sapienza, via web. Como gosto muito de rádio, fiz muitas palestras para crianças sobre o assunto. $\mathrm{O}$ trabalho com a rádio é vasto, pois é possível envolver crianças de 4, 5, até os 17 anos. O interesse de cada público é diferente, dependendo do tipo de meio que você usa. Como a comunicação atual dá destaque à imagem, as crianças se interessam muito por atividades com vídeo, câmera, ações práticas. Já os pais querem aprender a usar os meios para se comunicarem com os filhos.

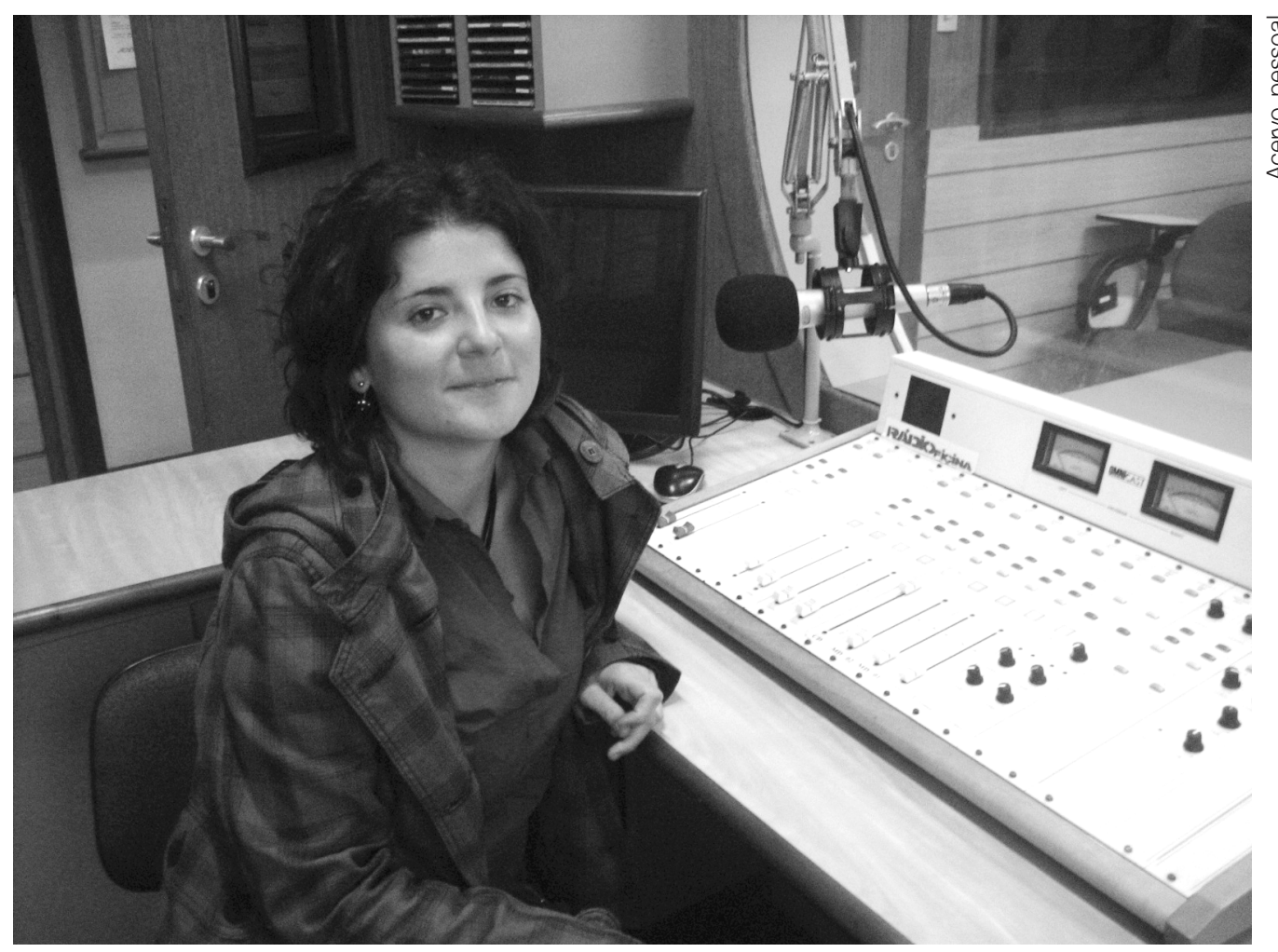

Isabella Bruni no estudio da Radioficina, durante a visita organizada por Nas Ondas do $R$ dio e Unesco.

\section{C\&E: Por que a escolha do Brasil como campo de estudo?}

Isabella: Escolhi vir ao Brasil porque fiz um laboratório chamado Educom.rádio, e Educom é também o nome do meu grupo de pesquisa sobre educomunicação em Roma. Pesquisando na internet, vi que este era o nome do projeto da Secretaria Municipal de Educação em parceria com a Universidade de São Paulo. Interessa-me muito a perspectiva sulamericana da educomunicação, que, a meu ver, é muito relacionada às questões de Direitos Humanos. O próprio projeto Educom é grandemente relacionado à cultura de paz. Tenho grande afinidade com esse enfoque de trabalho ligado à liberdade, ao desenvolvimento. Sendo 
assim, entrei em contato com os responsáveis pelo projeto no Brasil e, quando vi que havia a possibilidade de desenvolver a pesquisa para uma tese em outro país, apresentei a proposta de projeto acadêmico e ganhei a bolsa para vir para cá.

C\&E: Quais as principais diferenças entre o trabalho realizado aqui e o que vivenciou na Itália?

Isabella: Diante do que tenho visto e estudado, percebo que existe relação entre todos os pensadores e estudiosos deste tema nos países da América do Sul. Acredito que o trabalho desenvolvido aqui, nesse sentido, seja mais abrangente do que na Itália e na Europa. Na Itália, os educadores trabalham a educomunicação por meio de palestras e laboratórios, tentando unir teoria e prática. Procuram seguir o conceito do learning by doing - aprender fazendo. Os projetos envolvendo rádio e educação são desenvolvidos na escola, em associações ou em ONGs. Geralmente são atividades à parte do currículo, com um tempo de duração predeterminado, nunca muito longo - no máximo trinta horas. O trabalho na Itália é desenvolvido, principalmente, em torno de bases teóricas. Lá, os meios de comunicação ainda são vistos como poderosos e perigosos - recursos que, nas mãos das crianças, podem tornar-se um problema. Não é muito desenvolvida a ideia de mídia como arte, expressão, meio para que a criança se relacione com outras pessoas, para que conheça o mundo. $\mathrm{O}$ conceito de apropriação dos meios está se propagando por lá somente agora,

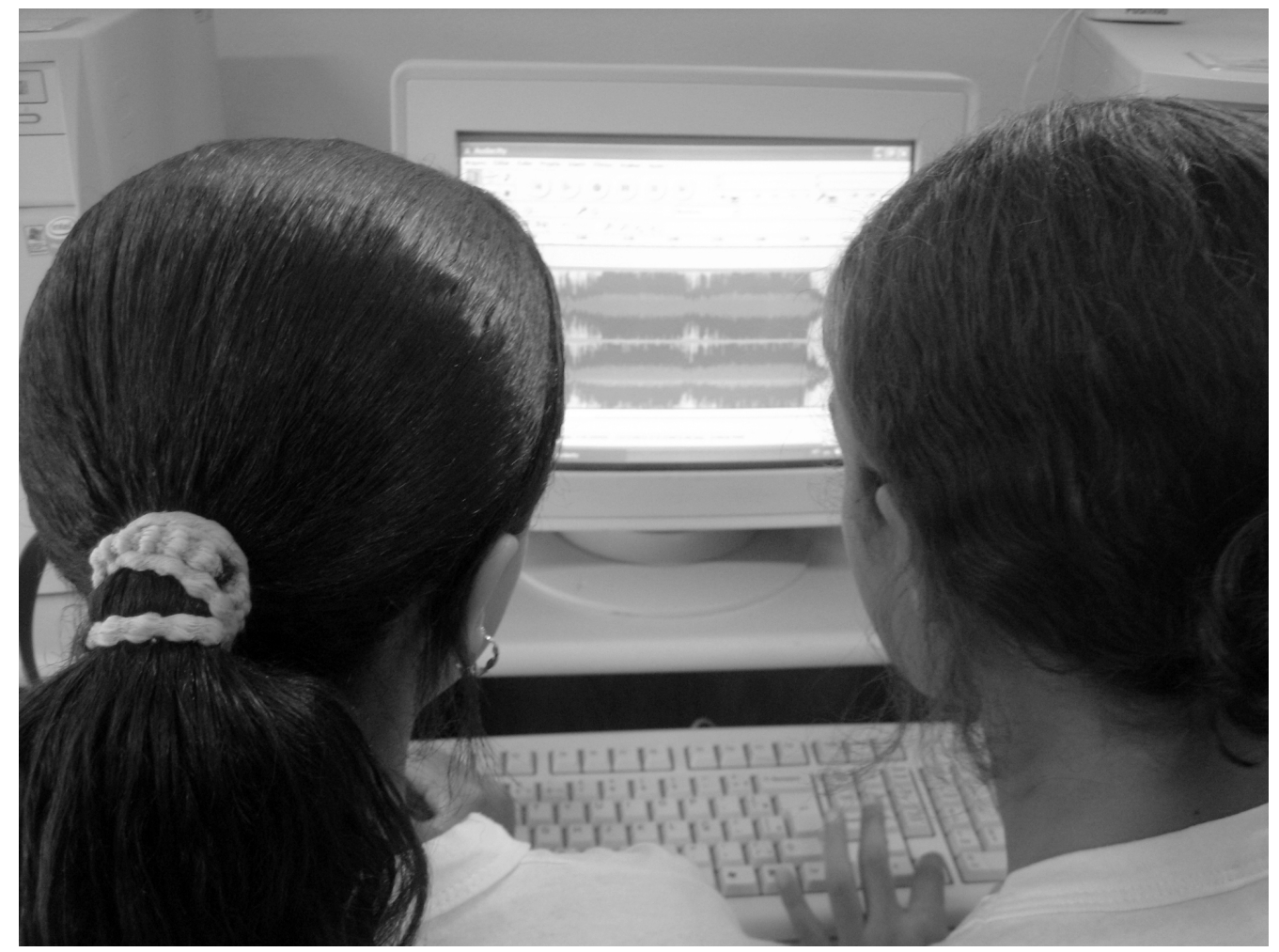

Alunos da EMEF Artur Neiva recebem forma o para trabalhar com o software Audacity, um editor de udio completo e gratuito que permite tocar $\mathrm{m}$ sicas, gravar sons, importar, exportar e converter arquivos nos formatos WAV, AIFF, MP3 e OGG. 
comunicação \& educação • Ano XV • Número 1 • jan/abr 2010

com a vinda da internet e do computador. Quando se trabalha com meios tradicionais, isso existe menos. Já quando se trabalha com computador, pode-se falar de ecossistema de comunicação, de relações nos meios de comunicação, das possibilidades que eles abrem, e não dos riscos que têm.

C\&E: Você considera que o ensino formal ainda não aproveita as possibilidades que as novas mídias oferecem?

Isabella: $\mathrm{O}$ uso das novas mídias na Itália é mais frequente em projetos de educomunicação realizados por associações e ONGs que trabalham com ferramentas de linguagem de expressão. Na escola, porém, só se consegue aplicar a educomunicação dentro dos moldes tradicionais de ensino das mídias - e, ainda assim, isso não é muito comum. Existe, por exemplo, um projeto para realizar um telejornal em aula. Então se começa do básico: o que é uma notícia, como se deve fazer para transmitir essa notícia para outra pessoa, como o trabalho do emissor vai modificar a notícia e transformá-la numa opinião. É mostrado o processo de construção de um telejornal para a criança, seguido de sua realização prática. Assim se desenvolve uma visão crítica: nem tudo que se fala na televisão é verdade; às vezes uma coisa não é notícia, mas sim opinião do jornalista ou do dono da emissora; objetividade não existe e há coisas que são verdade e outras que não são. Ou seja, mostramos como se constrói a apresentação da realidade nos meios de comunicação. Mas não há muita ênfase na apropriação dessas mídias pelo próprio aluno, para que ele mesmo construa sua comunicação.

C\&E: Ainda assim, é um conteúdo bastante profundo para ser abordado em sala de aula.

Isabella: Sim, mas esse tipo de estudo costuma ser iniciativa de professores ou ONGs, por meio de projetos específicos. Mas não faz parte, ainda, do currículo regular da escola. Há um ano, foi realizada na Itália uma reforma chamada Nuovo Obbligo di Formazione - fundamentada na ideia de que estudar é um direito e também uma obrigação. A partir dessa reforma, baseada nas competências da comunicação e da cidadania, é possível que aumente o incentivo, junto aos professores, em se trabalhar com os meios de comunicação. Porém, isso está começando agora, com professores que, de qualquer maneira, ainda possuem a formação antiga. Por enquanto, quando acontece o destaque dentro das aulas, é porque um professor considera isso importante. A principal condição para o fortalecimento da nova diretriz é a mudança na escola, que é uma instituição muito antiga, burocrática. Por isso, deve ser uma mudança de grão em grão. Recentemente, a Agência do Ministério passou a encaminhar verbas para a realização de projetos nas escolas. Acompanhei esse processo por meio da Associação Nacional de Educação dos Meios e de Comunicaçãoํㅜ que é a principal associação nacional da área, fundada há dez anos. Essa iniciativa da Agência do Ministério, acredito, foi a primeira no sentido de trabalhar competências, linguagens diferentes. E é um projeto do Ministério, ou seja, uma

1. Disponível em: <http:// www.medmediaeducation.it>. política pública que começa a se direcionar para isso. 
Educomunicação é para todos • Juliana Winkel

C\&E: Como será recebido esse novo movimento? Quais as dificuldades?

Isabella: A escola italiana é muito tradicional. Não há, como aqui, um professor de informática educativa. Geralmente, é o professor de matemática que desenvolve as aulas de informática, em linguagem tradicional. Eu, por exemplo, usei o Pascal* em aulas de informática na Itália. E foi um trabalho bem pontual, para aprendermos a utilizar o programa, não para nos apropriarmos da tecnologia - fazer fotos, vídeos ou algo assim. Na Itália, o computador fica no laboratório, uma área fechada que só se pode acessar com o professor. Lá, ainda prevalece na escola a cultura do livro. Considero a cultura literária fundamental, pois é a cultura da linearidade, do pensamento analítico. As escolas que cursei na Itália possuem uma cultura literária muito forte. No colégio clássico, estuda-se latim e grego. Isso possibilita ao aluno desenvolver um método de estudo, de análise da realidade e de pensamento crítico. Acredito na cultura do livro. Mas, atualmente, a criança tem contato primeiro com a televisão e depois com o livro. É preciso enfrentar essa realidade. E o computador é um dado novo nessa história, porque a internet é uma ferramenta que se pode usar para explorar o mundo, mais do que a televisão. A televisão não é de todo negativa, porque você vê imagens de outros países, conhece outras culturas. Contudo, com a internet, a criança pode se sentar na frente do computador e escolher as imagens que deseja ver. Essa possibilidade de exploração é muito importante. Sem contar que a linguagem do computador não é só de imagem e de som. É multimídia - nela você tem que escrever e ler de outra forma. É diferente dos livros, porém, sempre é uma capacidade que você vai adquirir. Às vezes é melhor saber falar uma coisa em cinco palavras do que em uma página. Depende de como você se apropria da tecnologia.

C\&E: O uso dessas novas mídias passa, necessariamente, por uma revisão dos modelos educacionais?

Isabella: A educomunicação já está num paradigma diferente, construtivista. É preciso mudar a cabeça e a postura de um professor para que ele faça educomunicação de verdade. Mais do que isso, é essencial também mudar o modelo e o objetivo da escola. Por isso é tão difícil fazer uma política pública forte nessa área: porque é necessário rever tudo, passando do modelo de transmissão de conceitos e saberes a um modelo de construção conjunta do saber trabalhando as competências das pessoas, dando a elas o método e depois as deixando agir. Somando-se a isso, há a exigência curricular: o professor tem de chegar ao final do ano tendo abordado uma quantidade determinada de assuntos, e é avaliado segundo o que faz ou não dentro do programa. Assim, a educomunicação se concentra nos projetos optativos, por conta de um problema de cronograma. Aqui em São Paulo, o projeto Educom.rádio já se transformou em uma política pública. Pode ter suas limitações, mas de qualquer forma houve um grande investimento em formação e em equipamentos. Penso que, no Brasil, as pessoas entendem melhor o propósito disso - um investimento no saber para a cidadania do futuro. As pessoas querem trabalhar no projeto porque veem a utilidade dele para si mesmas, mais do que para a instituição
* Linguagem de programação estruturada, que recebeu este nome em homenagem ao matemático Blaise Pascal. Foi criada em 1970 pelo suíço Niklaus Wirth, tendo em mente encorajar o uso de código estruturado para o ensino de linguagens de programação. N.E. 
ou para a escola. Participam da rádio porque com ela aprendem a falar, a lidar com o computador, a entrevistar pessoas. Pensam: "Passarei a ter meus direitos porque poderei falar alguma coisa”. Acho que o sentido do projeto Educom.rádio é esse: fazer com que os alunos percebam que têm importância e que podem falar o que estão pensando.

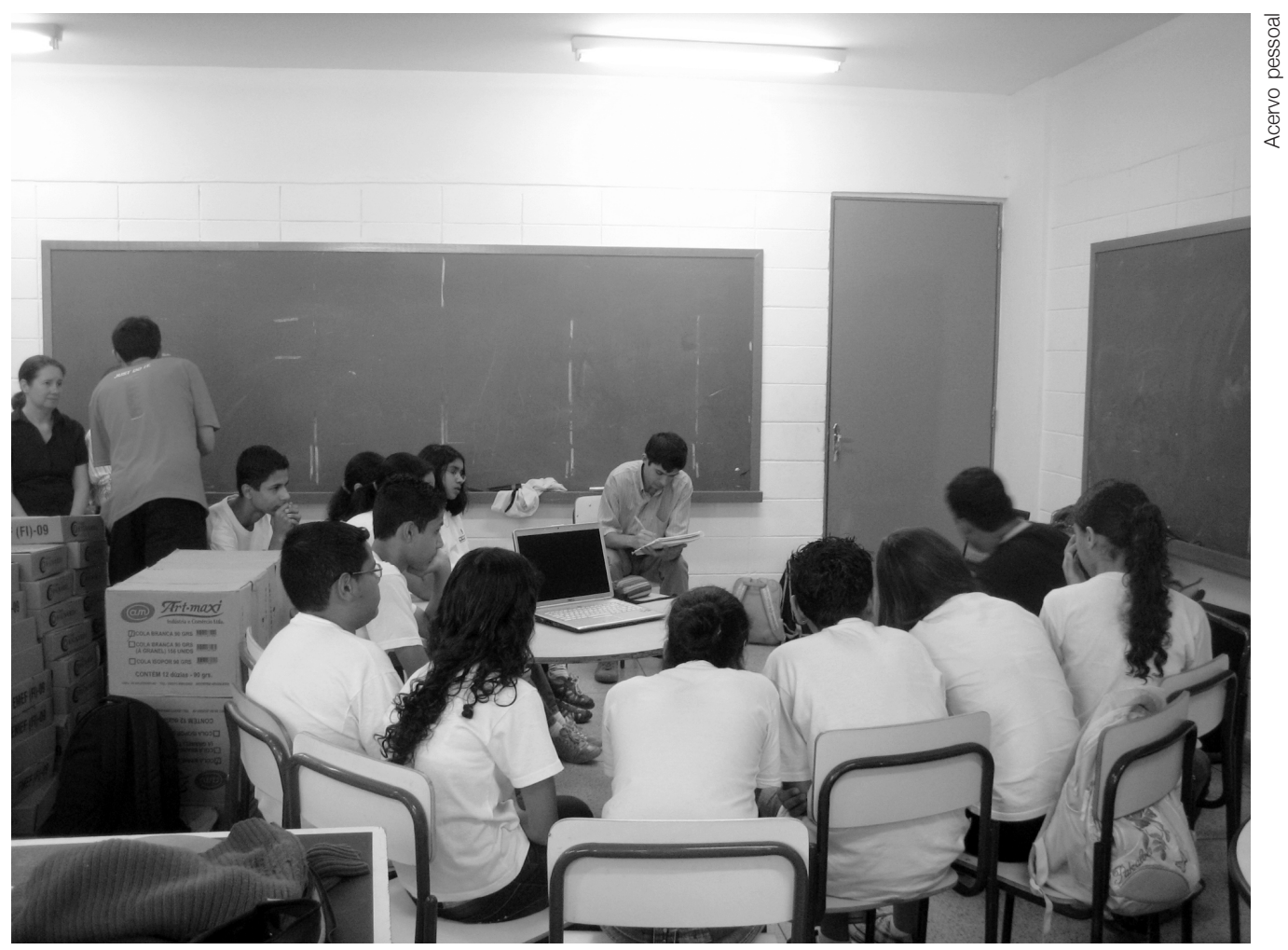

EMEF Gianfranco Guarnieri: alunos e professores recebem forma o sobre $r$ dio escolar.

\section{C\&E: No caso do Brasil, isso tem a ver também com o perfil social dessas comunidades?}

Isabella: Na minha pesquisa, vejo que as escolas em que o projeto funciona melhor são as mais pobres, de periferia. São as que precisam mais de comunicação interna, em que os meninos não têm outras coisas para fazer, não podem pagar para praticar um esporte. Com certeza, o bom desempenho da rádio tem relação com a questão social. Ao mesmo tempo, isso pode trazer algum conflito entre professores e alunos, já que o professor tem que mudar sua postura, deixando que os meninos falem. Na Itália, o professor fala e os alunos escutam, e só. São poucos os que fazem um trabalho mais prático, contemplando outras aprendizagens. Trabalhar ao lado do aluno, fazendo a mesma coisa em conjunto, é algo novo. Pode ser, por exemplo, que o aluno saiba lidar com o computador muito melhor do que ele. Então o professor deve ser um facilitador, e não estar acima do aluno, como detentor do saber. Essa horizontalidade é muito difícil, inclusive para os alunos. Se você trabalha com um aluno que já está na oitava série, ele se acostumou com o sistema vertical da escola. É difícil mudar de postura, se acostumar com essa liberdade. 


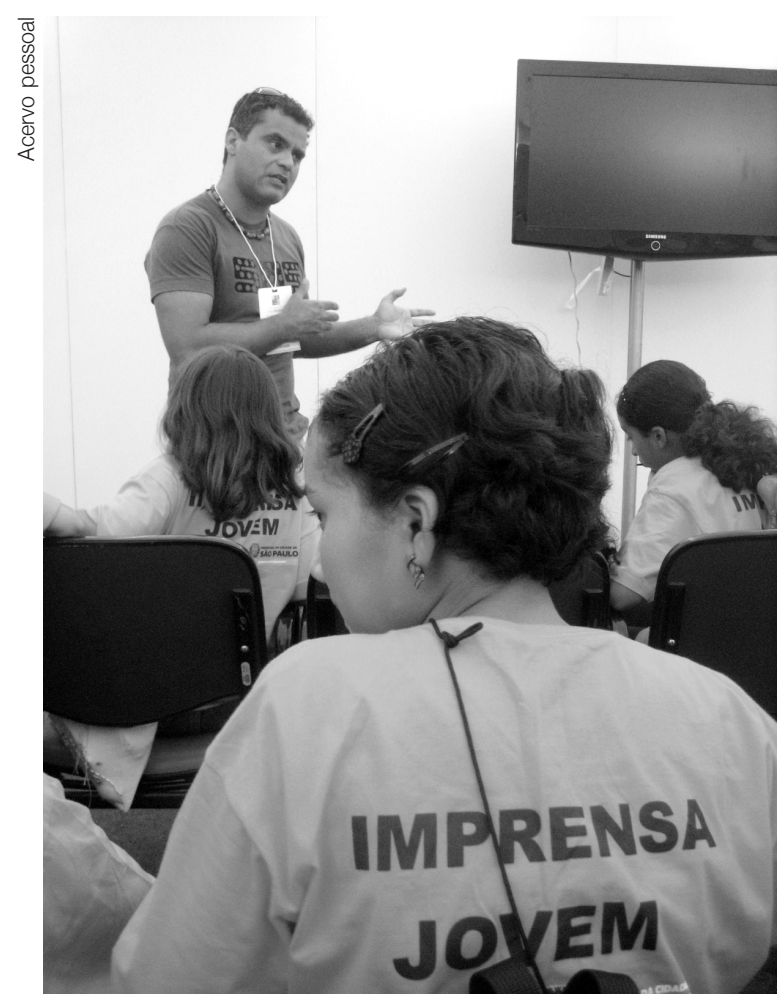

Cobertura jornal stica do Congresso de Tecnologia Educativa Interdid tica 2009, realizada pelas equipes da Imprensa Jovem: rep rteres adolescentes, entre 10 e 14 anos, integrantes do programa Nas Ondas do $R$ dio, que tamb $m$ utiliza as tecnologias da informa o e a comunica o na cobertura de eventos educativos.

C\&E: Qual a importância da vivência no Brasil dentro da pesquisa que você está desenvolvendo?

Isabella: $\mathrm{O}$ objetivo da minha pesquisa é estabelecer uma comparação entre o que é feito na Itália e o projeto Educom.rádio. O projeto Educom.rádio está em vias de se juntar ao projeto da Unesco sobre Segurança Humana. Estive especialmente nas escolas do Conjunto Habitacional José Bonifácio, que fica em Itaquera - uma área que foi escolhida devido ao alto nível de violência, um dos focos do projeto de Segurança Humana. O trabalho desenvolvido aqui será um modelo para a Itália, porque lá os projetos de educomunicação são de menor alcance. Pretendo fazer a comparação entre dois projetos de rádio web em escolas diferentes. O primeiro, no norte da Itália, funciona no sistema radioweb podcast e é organizado por um professor. O outro projeto, do sul, foi organizado em uma rede de escolas com o objetivo de combater a violência gerada pela máfia. Este é mais parecido com o Educom.rádio, pois envolve um número maior de escolas e foco na cultura de paz. O projeto que acompanho no norte da Itália surgiu porque um dos alunos teve um acidente grave e não pôde assistir às aulas por seis meses. Então, o professor e os colegas decidiram fazer uma rádio escolar para transmitir as aulas para ele, que estava no hospital. Já nas escolas do sul, no projeto contra a máfia, existe uma articulação maior no combate a homicídios, por meio de associações. Quem faz a rádio são os alunos e, paralelamente, existe um site onde se pode escutar as transmissões e onde ocorre a troca de ideias entre as escolas. É uma rede que envolve toda a comunidade. O Educom.rádio servirá como modelo por já ser desenvolvido há 
muito tempo - e por, recentemente, ter começado a utilizar as ferramentas do computador. Já operou com rádio virtual, blog, e trabalha com novos meios. Desde o começo de 2001 até agora, passou por muitas fases. Podemos acompanhar exatamente o desenvolvimento de uma rádio e prever, de certa forma, quais serão os problemas, trabalhando com o professor e com os alunos, tanto com a rádio normal como com a virtual. Meu trabalho é de observadora. Quando você está de fora, apresenta um olhar neutro sobre o processo e, às vezes, até uma ideia sobre a qual quem está envolvido no projeto não havia pensado. $\mathrm{O}$ que quero fazer é dar essa avaliação às pessoas para melhorar o projeto. Depois que apresentar o resultado da pesquisa, em fevereiro de 2010, pretendo realizar um projeto nessa linha com o Ministério, sobre educomunicação e meio ambiente. É muito gratificante quando se consegue trazer à prática os projetos que se delineou. 